Research Article

\title{
Experimental Study on Chloride Stress Corrosion Cracking Sensitivity of 316L Stainless Steel
}

\author{
Fei Chen (D) \\ Sichuan to Eastern China Gas Transmission Pipeline Co., Ltd., Wuhan 430020, China \\ Correspondence should be addressed to Fei Chen; cqds_chenf@163.com
}

Received 3 December 2020; Revised 26 February 2021; Accepted 11 March 2021; Published 22 March 2021

Academic Editor: Yi-Qing Ni

Copyright (c) 2021 Fei Chen. This is an open access article distributed under the Creative Commons Attribution License, which permits unrestricted use, distribution, and reproduction in any medium, provided the original work is properly cited.

\begin{abstract}
The slow-strain-rate tensile test was used to study the chloride stress corrosion cracking (SSC) behavior of 316L stainless steel under the simulated condition of a $\mathrm{CO}_{2}$ gas field in the Tarim Basin, and the effects of $\mathrm{CO}_{2}, \mathrm{Cl}^{-}$concentration, and temperature on the sensitivity of SCC were discussed. The results show that the increase of $\mathrm{CO}_{2}$ content has no apparent influence on the chloride SCC sensitivity of 316L stainless steel. With the rise in temperature, chloride SCC's sensitivity increases, and the change in the SCC sensitivity index $I_{\text {scc }}$ is noticeable. When the concentration of $\mathrm{Cl}^{-}$increases, the sensitivity of chloride SCC also increases. The degree of influence of the three factors on the experimental results can be ranked as follows: temperature $>\mathrm{Cl}^{-}>\mathrm{CO}_{2}$. In this experiment, when the partial pressure of $\mathrm{CO}_{2}$ is $0.1 \mathrm{MPa}$, the temperature is $65^{\circ} \mathrm{C}$, the concentration of $\mathrm{Cl}^{-}$is $1,20,000 \mathrm{mg} / \mathrm{L}$, and $I_{\text {scc }}$ of $316 \mathrm{~L}$ tensile samples has a maximum of $26.8 \%$.
\end{abstract}

\section{Introduction}

Stress corrosion cracking (SCC) refers to the phenomenon of crack nucleation and expansion and subsequent fracture of materials under the joint action of environmental media and stress. Stress and corrosion are synergistic to promote each other, and they are indispensable. Chloride SCC refers to the fracture phenomenon of metal under corrosion media's combined action containing $\mathrm{Cl}^{-}$and stress. Failure accidents caused by chloride SCC have occurred in 316L composite pipe.

The factors influencing stress corrosion can be divided into three categories: stress, environment, and metallurgy. The environmental factors, which affect the SCC of metals, are mainly discussed. In general, the higher the temperature is, the stronger the stress corrosion sensitivity will be. Some scholars think that the SCC process of austenitic stainless steel in a chloride corrosion medium can occur only when the temperature exceeds $80^{\circ} \mathrm{C}$. But, SCC of austenitic stainless steel was also found at room temperature. Cheng [1] believes that the higher the dissolved oxygen content is in the solution, the more easily SCC can occur. In a fully deoxygenated corrosion medium, SCC is rare. Ueda et al. [2] found that the super $13 \mathrm{Cr}$ stainless steel is susceptible to SCC in the completion fluid of $\mathrm{CaCl}_{2}$ containing $\mathrm{CO}_{2}$ and $\mathrm{H}_{2} \mathrm{~S}$ gas. Mancia and Liu [3,4] found that $13 \mathrm{Cr}$ steel has a high sensitivity to stress corrosion when $\mathrm{H}_{2} \mathrm{~S}$ exists, and the cracking is inhibited after the injection of $\mathrm{CO}_{2}$. $\mathrm{Li}$ [5] has studied the early electrochemical corrosion behavior at the crack tip of 316L stainless steel in a sodium chloride solution under different stresses. He found a severe stress concentration at the crack tip, along with the stress load raising and anodic dissolution rate increasing, and the crack tip's electrochemical corrosion has a close relationship with the stress concentration and distribution of the crack tip. Li et al. [6] studied the process of 304L stainless steel from pitting to stress corrosion and proposed roughly dividing the SCC process of austenitic stainless steel in the environment containing chloride ions into two stages: (1) damage and pitting of the metal surface passivation film and (2) the bottom of the pit acting as a crack source and expanding to SCC.

\section{Experimental Scheme}

2.1. Experimental Apparatuses. The main instruments are a universal testing machine (Figure 1(a)), a slow-strain-rate 


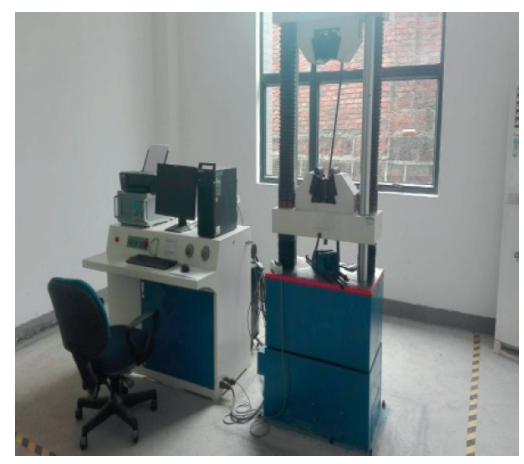

(a)

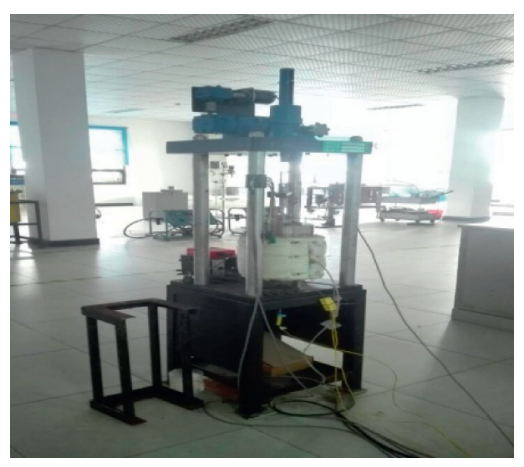

(b)

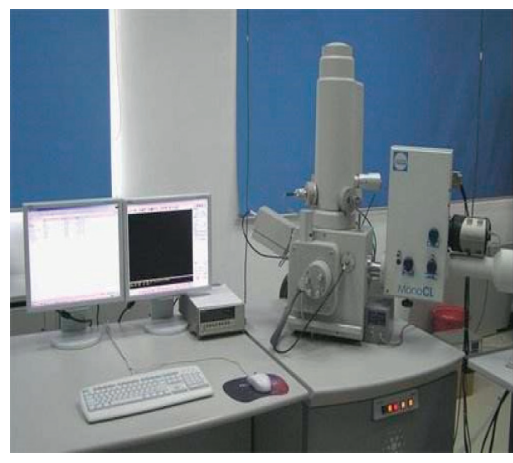

(c)

FIGURE 1: Instruments for stress corrosion experiment: (a) universal testing machine; (b) slow-strain-rate tensile testing machine; (c) scanning electron microscopy.

tensile testing machine (Figure $1(\mathrm{~b})$ ), a scanning electron microscopy (Figure $1(\mathrm{c})$ ), a CS electrochemical workstation, and a thermostatic water bath.

2.2. Experimental Sample. The weld zone is the weak area of corrosion of $316 \mathrm{~L}$ stainless steel, and $316 \mathrm{~L}$ welded joints are often sensitive to local corrosion [7, 8]. Therefore, 316L stainless steel samples with weld seams were used as experimental materials. The composition of 316L stainless steel is listed in Table 1. The material components of weld seams are listed in Table 2.

According to the recommended sample size of NACETM-0198, the total length of the sample is $80 \mathrm{~mm}$, the gauge length is $25.4 \mathrm{~mm}$, and the diameter of the tensile zone is $3.81 \mathrm{~mm}$. The sample size is shown in Figure 2(a). The samples were polished to a bright color by Grit 400, 600, 800, and 1,200 $\mathrm{SiC}$ papers, and then they were cleaned with distilled water and $99.5 \%$ ethanol solution. Diameters and lengths of the samples were measured and recorded. The prepared slow tensile test sample is shown in Figure 2(b).

2.3. Experimental Reagent. The experimental solution should be consistent with the water produced in the field in terms of ion type, $\mathrm{pH}$ value, concentration, and total mineralization. Given the experiment's times and feasibility, a water sample produced in the Dabei gas field was used as the experimental reagent in this paper, and four levels of $\mathrm{Cl}^{-}$ concentrations were set according to the testing scheme. The experimental solution was prepared with three-stage distilled water, and pure chemical reagents were used. After preparation, boric acid was used to adjust the $\mathrm{pH}$ value to 6.28 , and then the experimental solution was placed in a dry and cool place for standby. The composition of the experimental solution is listed in Table 3.

2.4. Experimental Principles and Procedures. The slowstrain-rate tensile test (SSRT) was used to evaluate the stress corrosion sensitivity of materials. SCC will significantly decrease mechanical performance, such as elongation rate, section shrinkage rate, maximum tensile strength, and fracture absorption energy. The more the factor decreases, the higher the SCC sensitivity is. At the same strain rate, the shorter the fracture time is, the higher the sensitivity of SCC.

An SSRT determined the stress-strain curve of $316 \mathrm{~L}$ stainless steel weld samples under simulated conditions of different $\mathrm{CO}_{2}$ partial pressures, different temperatures, and different $\mathrm{Cl}^{-}$concentrations. The sample was clamped onto a fixture located in the high-pressure reaction kettle. After the experimental medium was added to the reaction kettle, the top cover was tightened and sealed, the exhaust valve was opened, the air in the reaction kettle was exhausted by adding nitrogen, and then the exhaust valve was closed. Then, quantitative $\mathrm{CO}_{2}$ was added to increase the kettle's pressure; when the $\mathrm{CO}_{2}$ partial pressure reached the predetermined value, ventilation was stopped, and the intake valve was closed. The total pressure was controlled at $16 \mathrm{MPa}$. The experiment temperature was controlled by a heating sleeve outside the reaction kettle. The tensile rate was set as $4 e-6 \mathrm{~s}^{-1}$. Before the tensile test of slow-strain-rate, a tensile failure experiment of the $316 \mathrm{~L}$ stainless steel sample was conducted in the air to record its mechanical properties. The experimental data would be used as a blank control for the calculation of stress corrosion sensitivity. The experimental conditions were set as follows:

(1) For the first set of experiments to study the effect of $\mathrm{CO}_{2}$ partial pressure, the $\mathrm{CO}_{2}$ partial pressure was set to $0,0.1,0.2$, and $0.3 \mathrm{MPa}$, respectively, the temperature was set to $65^{\circ} \mathrm{C}$, and the $\mathrm{Cl}^{-}$concentration was $60000 \mathrm{mg} / \mathrm{L}$.

(2) For the second set of experiments to study the effect of temperature, the temperature was set to $25^{\circ} \mathrm{C}$, $45^{\circ} \mathrm{C}, 65^{\circ} \mathrm{C}$, and $85^{\circ} \mathrm{C}$, respectively, the $\mathrm{CO}_{2}$ partial pressure was $0.1 \mathrm{MPa}$, and the $\mathrm{Cl}^{-}$concentration was $60000 \mathrm{mg} / \mathrm{L}$.

(3) For the third set of experiments to study the effect of $\mathrm{Cl}^{-}$concentration, the $\mathrm{Cl}^{-}$concentration was set to $60,000,80,000,1,00,000$, and $1,20,000 \mathrm{mg} / \mathrm{L}$, respectively, the $\mathrm{CO}_{2}$ partial pressure was $0.1 \mathrm{MPa}$, and the temperature was set to $65^{\circ} \mathrm{C}$.

2.5. Selection and Calculation of Sensitivity Index. Based on related research results, the metal SCC sensitivity index $\left(I_{\mathrm{scc}}\right)$ 
TABLE 1: Composition of 316L stainless steel.

\begin{tabular}{lccccccccc}
\hline Composition & $\mathrm{C}$ & $\mathrm{Cr}$ & $\mathrm{Ni}$ & $\mathrm{Mo}$ & $\mathrm{S}$ & $\mathrm{Mn}$ & $\mathrm{Si}$ & $\mathrm{P}$ & $\mathrm{Fe}$ \\
\hline Percentage & 0.025 & 16.80 & 13.20 & 2.38 & 0.014 & 1.17 & 0.029 & 0.031 & 66.35 \\
\hline
\end{tabular}

TABLe 2: Material components of weld seams.

\begin{tabular}{lccr}
\hline Weld bead & Type & Brand & Acceptance standard \\
\hline Root weld & R316LT1-5 & ATS-F316L & AWS A5.22 \\
Seal weld & R309LT1-5 & ATS-F309L & AWS A5.22 \\
Transition weld & ER309LMo & ATS-309MoL & AWS A5.9 \\
Fill and cap & E5015 & CHE507 & GB/T5117-1995 \\
\hline
\end{tabular}

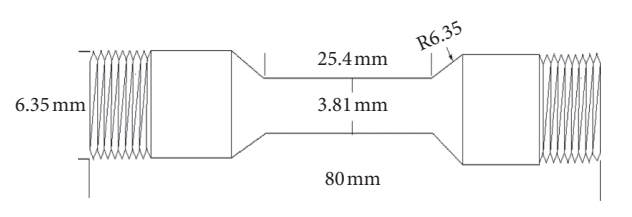

(a)

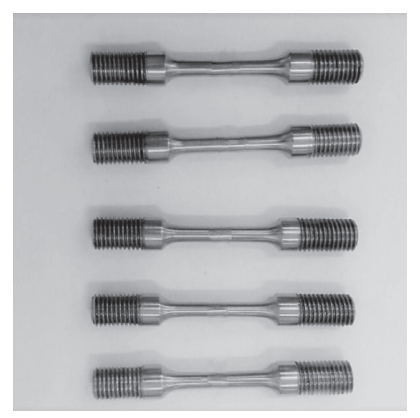

(b)

Figure 2: Tensile test samples of slow-strain-rate: (a) sample drawing; (b) sample.

TABLE 3: Ion concentration of reagents and used drugs.

\begin{tabular}{lccc}
\hline Ion & Concentration $(\mathrm{mg} / \mathrm{L})$ & Drugs & Drugs as required per liter $(\mathrm{g})$ \\
\hline $\mathrm{Ca}^{2+}$ & 7,030 & $\mathrm{CaCl}_{2}$ & 19.5 \\
$\mathrm{Mg}^{2+}$ & 760 & $\mathrm{MgCl}_{2} \cdot 6 \mathrm{H}_{2} \mathrm{O}$ & 6.4 \\
$\mathrm{SO}_{2}^{-4}$ & 670 & $\mathrm{Na}_{2} \mathrm{SO}_{4}$ & 1.0 \\
$\mathrm{HCO}^{-3}$ & 900 & $\mathrm{NaHCO}_{3}$ & 0.5 \\
\hline & 60,000 & $\mathrm{NaCl}$ & 74.9 \\
$\mathrm{Cl}^{-}$ & 80,000 & $\mathrm{NaCl}$ & 107.8 \\
& $1,00,000$ & $\mathrm{NaCl}$ & 140.7 \\
\hline
\end{tabular}

can be calculated by comparing the metal's characteristic parameters in the inert medium with those in the corrosive medium. The SCC sensitivity index $\left(I_{\text {scc }}\right)$ can be calculated according to the following equation:

$$
I_{\mathrm{scc}}=\frac{I_{\mathrm{air}}-I_{\text {corr }}}{I_{\mathrm{air}}} \times 100 \%
$$

where $I_{\text {air }}$ represents the experimental parameters in the inert medium and $I_{\text {corr }}$ represents the experimental parameters in the corrosive medium.

In this paper, the percentage elongation after fracture, $\delta_{5}$, of the tensile sample was selected as the SCC sensitivity index, and the chloride stress corrosion sensitivity of the 316L stainless steel tensile sample can be calculated by using the following formula:

$$
I_{\delta}=\frac{\delta_{\text {air }}-\delta_{\text {corr }}}{\delta_{\text {air }}} \times 100 \%,
$$

where $I_{\delta}$ is the stress corrosion cracking sensitivity index, $\delta_{\text {air }}$ is the elongation in the inert medium, and $\delta_{\text {corr }}$ is the elongation in the corrosive medium.

The formula for calculating the elongation after fracture of the sample is

$$
\delta_{5}=\frac{L_{1}-L_{0}}{L_{0}} \times 100 \% \text {, }
$$

where $L_{0}$ is the starting gauge length of the slow tensile test specimen and $L_{1}$ is the gauge length after fracture of the tensile test specimen.

The larger the $I_{\text {scc }}$ value, the greater the tendency of metal stress corrosion. According to previous research conclusions $[9,10]$, the general rules for using $I_{\mathrm{scc}}$ to characterize the sensitivity of SCC are as follows: when $I_{\text {scc }}$ is $<25 \%$, the metal has no apparent stress corrosion tendency; when $25 \%$ $<I_{\text {scc }}<35 \%$, the metal has a certain degree of stress corrosion tendency; and when $I_{\mathrm{scc}}$ is $>35 \%$, the metal has an evident stress corrosion tendency. 


\section{Experimental Results and Analysis}

3.1. Blank Tensile Test Results of 316L Stainless Steel. Tensile failure experiments were conducted on the $316 \mathrm{~L}$ sample in air, and the main mechanical properties of the sample are listed in Table 4.

\subsection{Influence of $\mathrm{CO}_{2}$ Partial Pressure on Stress Corrosion Sensitivity}

3.2.1. Experimental Results. The 316L stainless steel weld tensile samples were set at $65^{\circ} \mathrm{C}$, and the $\mathrm{Cl}^{-}$concentration was set to $60,000 \mathrm{mg} / \mathrm{L}$. The stress-strain curve of the sample in the simulated solution under different $\mathrm{CO}_{2}$ partial pressures is shown in Figures 3. Figure 4 displays the SEM images of fracture surface morphology of tensile test coupons under different $\mathrm{CO}_{2}$ partial pressure. The test results for the main mechanical properties of $316 \mathrm{~L}$ stainless steel weld samples under different $\mathrm{CO}_{2}$ partial pressures are listed in Table 5.

It can be seen from Figure 3 that, with the increase of $\mathrm{CO}_{2}$ partial pressure, the tensile strength and elongation of the 316L stainless steel weld sample are not apparent. This indicates that $\mathrm{CO}_{2}$ has little effect on the SCC sensitivity of 316L stainless steel and can be regarded as an "inert gas". From Table 5 , it can be seen that, with the increase of $\mathrm{CO}_{2}$ partial pressure, the maximum tensile strength decreases first and then increases, but the change is small. The extension rate increases slightly but is less than 50\%. The section' shrinkage rate and fracture time fluctuate with the increase of $\mathrm{CO}_{2}$ partial pressure, but the change is not apparent. The section's shrinkage rate is relatively large, which indicates that $316 \mathrm{~L}$ stainless steel has a strong ability to withstand plastic deformation before fracture in this experiment .

\subsubsection{Analysis}

(1) At present, for $\mathrm{Cr}-\mathrm{Ni}$ austenitic stainless steel, the most accepted SCC mechanism is anode slippage dissolution. The occurrence of stress corrosion is directly related to the local dissolution of metal material. In the liquid-phase system containing $\mathrm{CO}_{2}$, the equilibrium conditions are relatively complex. $\mathrm{H}_{2} \mathrm{CO}_{3}, \mathrm{HCO}^{-3}, \mathrm{CO}_{2}^{-3}$, and $\mathrm{CO}_{2}$ in the solution will be directly or indirectly involved in the corrosion process as depolarizing agents, which will significantly affect the cathode's progress and rate reaction. Therefore, theoretically, increasing the partial pressure of $\mathrm{CO}_{2}$ will accelerate the cathode reaction, resulting in accelerated corrosion of metal materials.

(2) However, the results show that, for anodic dissolution stress corrosion, the stress corrosion crack's root is the pitting hole and microcracking on the material's surface. Therefore, the passive film greatly influences the sensitivity of chloride stress corrosion. In the $\mathrm{CO}_{2}$-saturated environment, $316 \mathrm{~L}$ has good passive film formation characteristics; that is, $\mathrm{CO}_{2}$ contributes to forming a $\mathrm{FeCO}_{3}$ passive film on the
TABle 4: Mechanical properties of blank tensile test of $316 \mathrm{~L}$ stainless steel.

\begin{tabular}{lc}
\hline Material mechanics property parameter & Experimental results \\
\hline Tensile strength $(\mathrm{MPa})$ & 607.0 \\
Yield strength $\left(R_{t 0.5}\right)(\mathrm{MPa})$ & 339.0 \\
Elongation $(A)(\%)$ & 62.4 \\
Reduction of area $(Z)(\%)$ & 86.1 \\
\hline
\end{tabular}

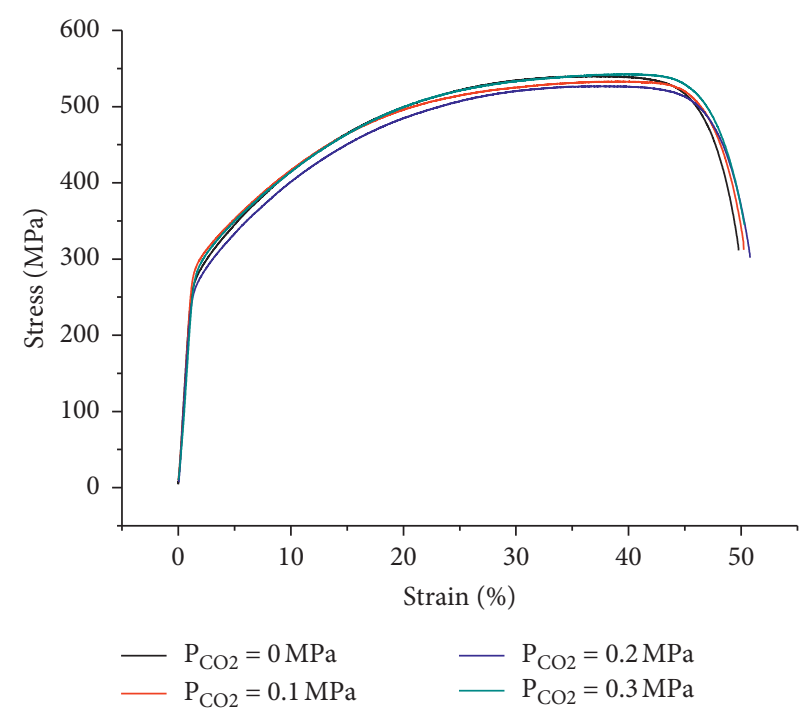

FIgURE 3: Stress-strain curve of 316L stainless steel at different $\mathrm{CO}_{2}$ partial pressure.

surface, thus playing a role in inhibiting local corrosion of 316L.

(3) However, under these experimental conditions $\left(65^{\circ} \mathrm{C}\right.$ and $\mathrm{Cl}^{-}=60,000 \mathrm{mg} / \mathrm{L}$ ), the surface passive film's nature is not stable and plastic deformation of the tensile specimen is serious by continuous external stress. This leads to constant mechanical damage of the passive film, limiting its ability to protect the $316 \mathrm{~L}$ matrix metal. Consequently, the results do not change obviously with the increase of $\mathrm{CO}_{2}$ partial pressure.

(4) Figure 5 shows the SCC sensitivity index $\left(I_{\text {scc }}\right)$ of $316 \mathrm{~L}$ stainless steel under different partial pressures of $\mathrm{CO}_{2}$ calculated according to equation (2). The following conclusions can be obtained from Figure 5 . When the partial pressure of $\mathrm{CO}_{2}$ increases from 0 to $0.3 \mathrm{MPa}$, the overall change in the stress corrosion sensitivity of the $316 \mathrm{~L}$ stainless steel tensile sample is not apparent, with a slightly decreasing trend, and the minimum value is $20.2 \%$ when $\mathrm{PCO}_{2}=0.2 \mathrm{MPa}$. According to the general rules of SCC sensitivity based on $I_{\text {scc }}$ value, no significant chloride SCC sensitivity is shown in the tensile samples of $316 \mathrm{~L}$ stainless steel under this experimental condition.

\subsection{Effect of Temperature on Stress Corrosion Sensitivity}

3.3.1. Experimental Results. The 316L stainless steel tensile sample was set in a simulated solution in which the $\mathrm{CO}_{2}$ 


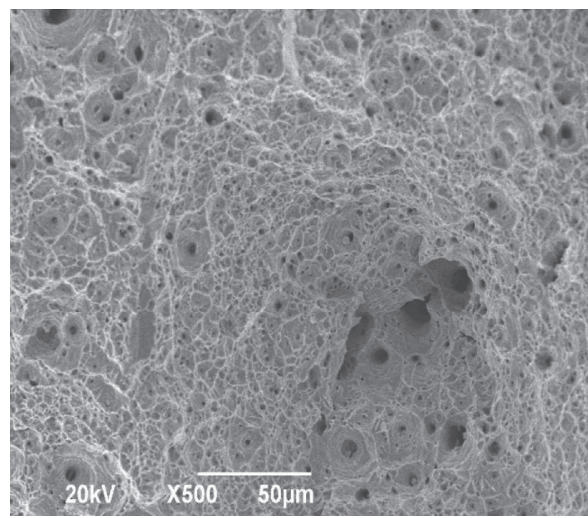

(a)

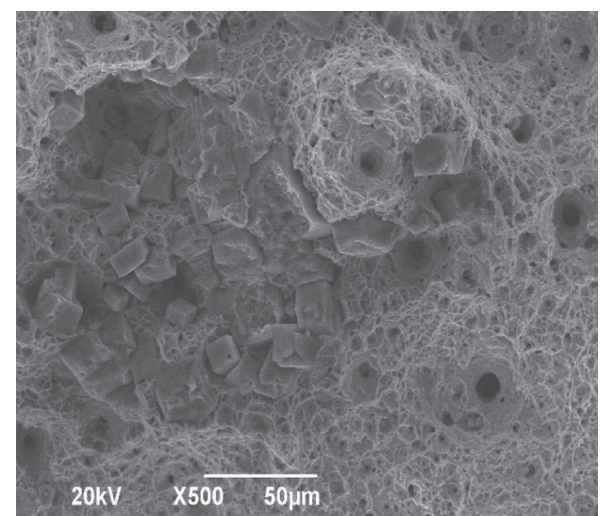

(b)

Figure 4: SEM images of fracture surface morphology of tensile test coupons $\left(T=65^{\circ} \mathrm{C}, \mathrm{Cl}^{-}=60,000 \mathrm{mg} / \mathrm{L}\right):(\mathrm{a}) \mathrm{PcO}=0.1 \mathrm{MPa}$; (b) $\mathrm{PCO}_{2}=0.3 \mathrm{MPa}$.

TABLE 5: Main mechanical properties of 316L stainless steel under different $\mathrm{CO}_{2}$ partial pressure.

\begin{tabular}{lcccc}
\hline $\mathrm{PcO}_{2}(\mathrm{MPa})$ & Tensile strength $\sigma_{b}(\mathrm{MPa})$ & Reduction of area $\psi(\%)$ & Elongation $\delta_{5}(\%)$ & Fracture time $(\mathrm{h})$ \\
\hline 0.0 & 539.0 & 84.8 & 48.9 & 35.0 \\
0.1 & 532.0 & 83.7 & 49.5 & 35.1 \\
0.2 & 526.0 & 85.0 & 49.8 & 34.6 \\
0.3 & 542.0 & 83.4 & 49.5 & 36.2 \\
\hline
\end{tabular}

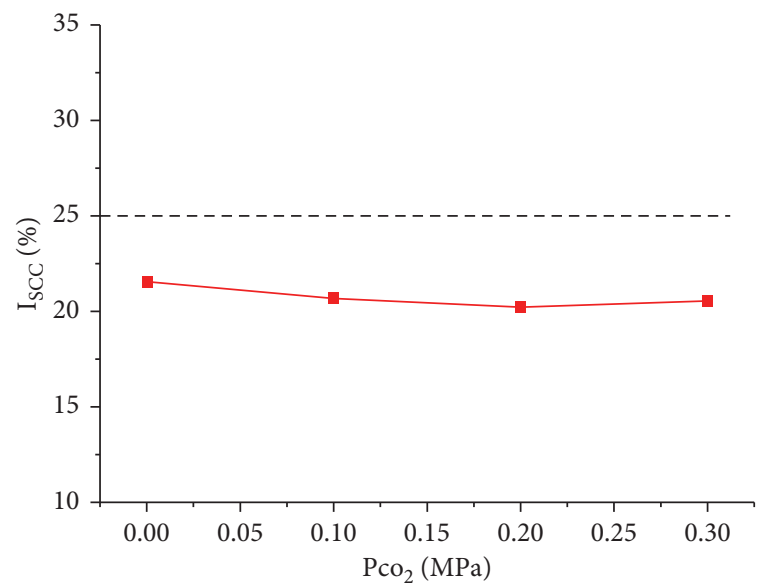

FIGURE 5: Stress corrosion cracking sensitivity index of $316 \mathrm{~L}$ stainless steel in different $\mathrm{CO}_{2}$ partial pressure.

partial pressure was $0.1 \mathrm{MPa}$, and the $\mathrm{Cl}^{-}$concentration was $60,000 \mathrm{mg} / \mathrm{L}$. The stress-strain curve for the sample in the simulated solution at different temperatures is shown in Figure 6. Figure 7 displays the SEM images of fracture surface morphology of tensile test coupons under different temperatures. The main mechanical properties of $316 \mathrm{~L}$ stainless steel at different temperatures are listed in Table 6.

As shown in Table 6 and Figure 6, the 316L tensile sample's experimental results vary significantly with temperature. When the temperature is $25^{\circ} \mathrm{C}$, the material's mechanical properties have a maximum value, which indicates that the sensitivity of SCC is minimal. When the temperature rises to $45^{\circ} \mathrm{C}$, none of the mechanical properties have changed much, indicating that the sample's mechanical

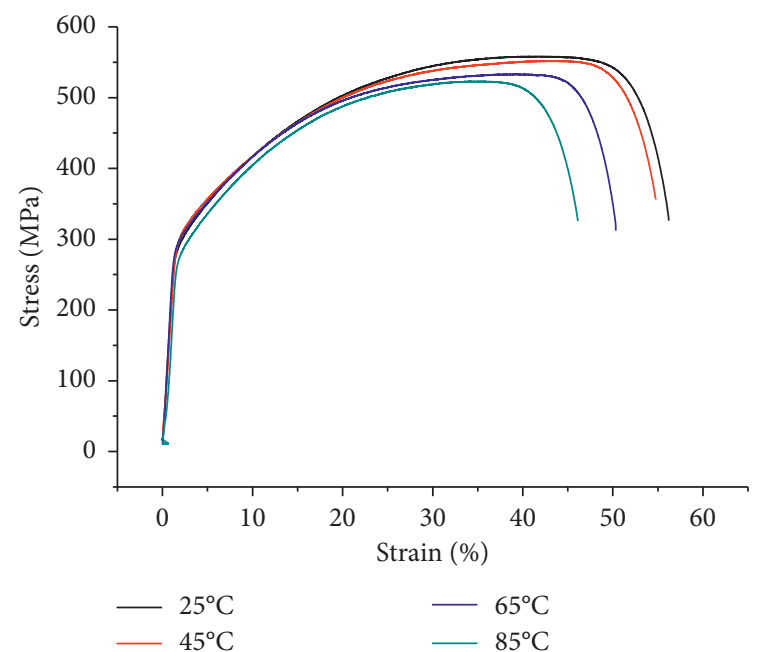

FIGURE 6: The stress-strain curve of 316L stainless steel at different temperatures.

properties and plastic deformation capability have not deteriorated significantly with the increase of temperature in this interval. However, when the temperature reaches $65^{\circ} \mathrm{C}$, many material properties are reduced considerably. The plastic deformation area in the stress-strain curve narrows significantly, elongation drops by nearly $5 \%$, and tensile strength decreases by $19 \mathrm{MPa}$. These changes demonstrate that the tensile samples' mechanical properties and their plastic deformation ability have deteriorated. When the temperature rises to $85^{\circ} \mathrm{C}$, the elongation further decreases, the fracture strain value is less than 0.5 , the plastic deformation of the material dramatically decreases, tensile strength falls from $532 \mathrm{MPa}$ at $65^{\circ} \mathrm{C}$ to $517 \mathrm{MPa}$, and section 


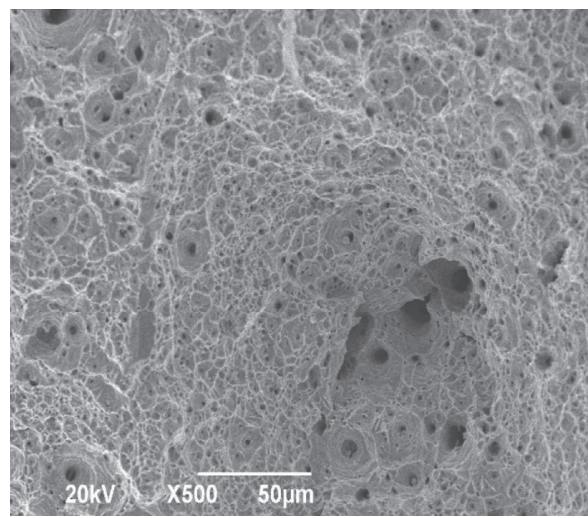

(a)

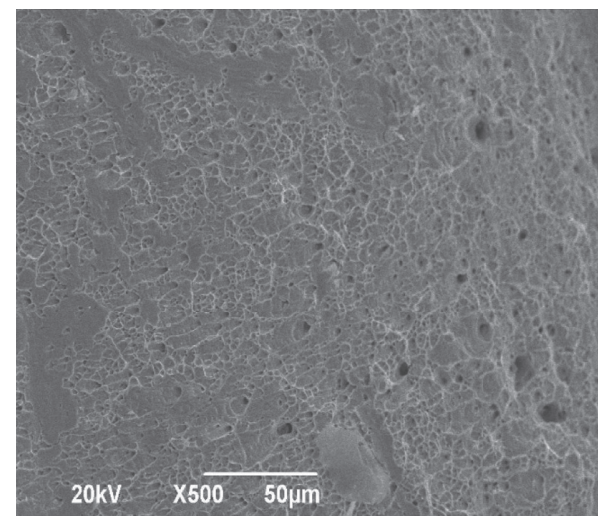

(b)

Figure 7: SEM images of fracture surface morphology of tensile test coupons $\left(\mathrm{Pco}_{2}=0.1 \mathrm{MPa}, \mathrm{Cl}^{-}=60,000 \mathrm{mg} / \mathrm{L}\right):(\mathrm{a}) \mathrm{T}=65^{\circ} \mathrm{C}$; (b) $\mathrm{T}=85^{\circ} \mathrm{C}$.

TABLE 6: Main mechanical properties of 316L stainless steel at different temperatures.

\begin{tabular}{lcccc}
\hline $\mathrm{T}\left({ }^{\circ} \mathrm{C}\right)$ & Tensile strength $\sigma_{b}(\mathrm{MPa})$ & Reduction of area $\psi(\%)$ & Elongation $\delta_{5}(\%)$ & Fracture time $(\mathrm{h})$ \\
\hline 25 & 558.0 & 84.8 & 56.2 & 36.3 \\
45 & 551.0 & 82.7 & 54.1 & 35.4 \\
65 & 532.0 & 83.7 & 49.5 & 35.1 \\
85 & 517.0 & 77.6 & 45.9 & 32.9 \\
\hline
\end{tabular}

shrinkage falls to $77.6 \%$ (from $83.7 \%$ at $65^{\circ} \mathrm{C}$ ). The onset time of breakage is significantly reduced to $32.9 \mathrm{~h}$.

3.3.2. Analysis. Based on the analysis of the experimental results, the influence of temperature on chloride SCC of 316L stainless steel is as follows:

(1) As we can see from Figures 6 and 8, when the experimental temperature is low $\left(<45^{\circ} \mathrm{C}\right), 316 \mathrm{~L}$ tensile samples have relatively low SCC sensitivity. This is because the passive film's properties on the material surface are stable, and its self-repair ability is stronger. With the temperature increase, the dynamic equilibrium of the dissolution and formation of the passive film is damaged, leading to a rise in the possibility of local corrosion. Under the action of continuous stress, high temperature speeds up the dynamic cycle of slippage-film rupture-dissolution-repassivation-slippage, and it shortens the time required for stress corrosion nucleation and expansion.

(2) Increasing the temperature will reduce the pitting breakdown potential Eb100 of 316L stainless steel, which will increase the possibility of pitting corrosion. Besides, the influence of temperature on the corrosion potential is more prominent under no oxygen or low oxygen content.

(3) Increasing the temperature will also increase the metal's surface-active point and accelerate the chemical reaction rate. It is known that there is a natural exponential relationship between crack growth rate and the complex reciprocal temperature; that is, an increase in temperature will accelerate the

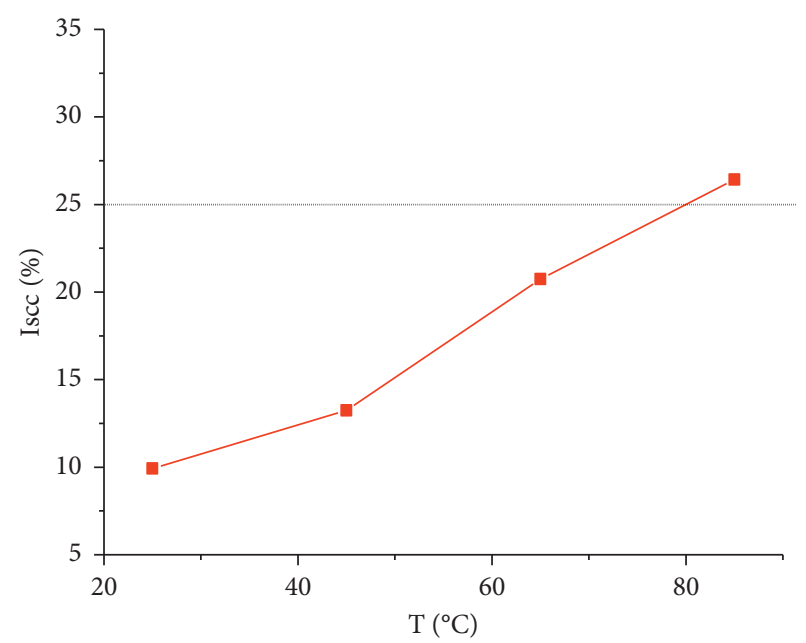

Figure 8: Stress corrosion cracking sensitivity index of $316 \mathrm{~L}$ stainless steel at different temperatures.

crack growth rate. Besides, the chemical adsorption capacity of $\mathrm{Cl}^{-}$at high temperatures is significantly enhanced, resulting in increased pitting sensitivity of 316L stainless steel and decreased pitting resistance. Under the action of continuous tensile stress, pitting extends to become microcracks and further evolves into SCC.

(4) The figures show the SCC sensitivity index $\left(I_{\text {scc }}\right)$ of $316 \mathrm{~L}$ stainless steel at different temperatures calculated according to equation (2). From Figure 6 to Figure 8 , we can conclude the following:

(i) When the temperature increases from $25^{\circ} \mathrm{C}$ to $85^{\circ} \mathrm{C}$, the stress corrosion sensitivity of $316 \mathrm{~L}$ 
stainless steel tensile samples significantly increases, demonstrating that, under the environment of a $\mathrm{CO}_{2}$ gas field in the Tarim Basin, the temperature is an essential factor influencing the occurrence of chloride SCC of $316 \mathrm{~L}$. The higher the temperature is, the more likely the SCC will occur.

(ii) The event of SCC of 316L stainless steel requires that a critical temperature value be reached. When the temperature is higher than this critical value, the material will exhibit a more obvious tendency for SCC. Under these experimental conditions, only when the temperature reaches $80^{\circ} \mathrm{C} 316 \mathrm{~L}$, stainless steel exhibits SCC tendency.

\subsection{Effect of $\mathrm{Cl}^{-}$Concentration on Stress Corrosion Sensitivity}

3.4.1. Experimental Results. The stress-strain curves of the 316L stainless steel tensile specimen in a simulated solution at a $\mathrm{CO}_{2}$ partial pressure of $0.1 \mathrm{MPa}$ and a temperature of $65^{\circ} \mathrm{C}$ at different $\mathrm{Cl}^{-}$concentrations are shown in Figure 9. The SEM images of fracture surface morphology of tensile test coupons under different $\mathrm{Cl}^{-}$concentrations are displayed in Figure 10. The main mechanical properties of the $316 \mathrm{~L}$ stainless steel weld sample at different $\mathrm{Cl}^{-}$concentrations are listed in Table 7.

As shown in Table 7 and Figure 9, the tensile strength of the 316L tensile sample decreases slightly with the increase of $\mathrm{Cl}^{-}$concentration, but the change is not significant. The minimum value is $517 \mathrm{MPa}$ when $\mathrm{Cl}^{-}$concentration is $1,00,000 \mathrm{mg} / \mathrm{L}$. The $\mathrm{Cl}^{-}$concentration in the solution has little effect on the $316 \mathrm{~L}$ stainless steel's ability to withstand maximum homogeneous plastic deformation between 60,000 and $1,20,000 \mathrm{mg} / \mathrm{L}$. The tensile samples' fracture strain decreases by a certain extent with the $\mathrm{Cl}^{-}$concentration increase, but the variation of the strain within the different $\mathrm{Cl}^{-}$concentration ranges is very different: the strain decreases significantly within the concentration range of 60,000 to $1,00,000 \mathrm{mg} / \mathrm{L}$. The increased $\mathrm{Cl}^{-}$concentration significantly influences the SCC sensitivity of 316L stainless steel in this concentration range. However, when the $\mathrm{Cl}^{-}$ concentration increases to $1,20,000 \mathrm{mg} / \mathrm{L}$, the strain change is not apparent. It can be seen from Table 7 that, with the increase of $\mathrm{Cl}^{-}$concentration, the section shrinkage rate of the sample will significantly deteriorate, which indicates that the local plastic deformation ability of the tensile sample is reduced dramatically. Besides, the tensile sample's fracture time tends to shorten overall, indicating that the material's SCC sensitivity increased.

\subsubsection{Analysis}

(1) The influence of $\mathrm{Cl}^{-}$concentration on the chloride SCC sensitivity of $316 \mathrm{~L}$ stainless steel is mainly manifested by the promotion of pitting corrosion and microcracks. Under the liquid environment of $\mathrm{Cl}^{-}$enrichment, $\mathrm{Cl}^{-}$selectively adsorbs on the weld and heat-affected zone with a rough surface and

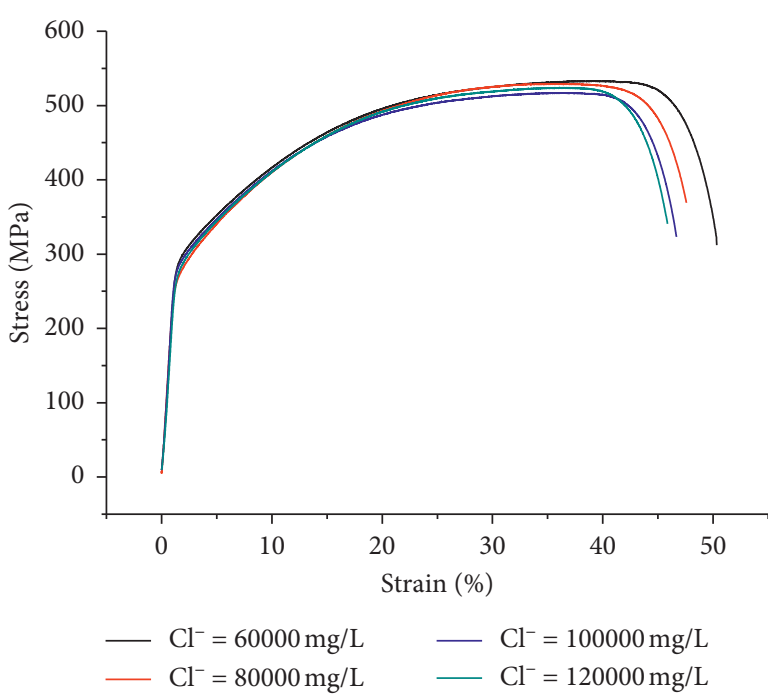

Figure 9: Stress-strain curves of 316L stainless steel at different $\mathrm{Cl}^{-}$ concentrations.

stress concentration. The $\mathrm{Cl}^{-}$can damage the local passive film of the stainless steel because of its small radius and strong penetration ability, so it is easier to enter the protective film formed by corrosion products. As the concentration of $\mathrm{Cl}^{-}$increases, its tendency to penetrate the metal surface film increases. At this point, the metal surface becomes the battery's anode, while the part that remains passive becomes the cathode area. Because of the continuous tensile stress on the sample, the tensile stress is likely to be locally concentrated at the point with pitting corrosion. The accelerated erosion pit will expand into a crack. $\mathrm{Cl}^{-}$will accumulate at the crack tip, promote the further expansion of the crack tip, reduce the strength and plastic deformation capacity of the material, and eventually cause SCC.

(2) The fracture analysis of numerous slow tensile specimens demonstrates that the metal has corroded before fracture. The corrosion products are mainly composed of $\mathrm{Fe}$ and $\mathrm{Cr}$ oxides, and the corrosion products do not contain or only contain a small amount of chloride. $\mathrm{Cl}^{-}$does not participate in the corrosion reaction but only plays the role of accelerating the corrosion reaction. However, when $\mathrm{Cl}^{-}$ concentration reaches a certain level, the acceleration effect is no longer noticeable.

(3) Figure 11 shows the SCC sensitivity index $\left(I_{\text {scc }}\right)$ of $316 \mathrm{~L}$ stainless steel at different temperatures calculated according to equation (2). The following conclusions can be obtained from Figure 11: when $\mathrm{Cl}^{-}$concentration increases from 60,000 to $1,20,000 \mathrm{mg} / \mathrm{L}$, the stress corrosion sensitivity of 316L stainless steel tensile specimens increases by a certain extent, and when $\mathrm{Cl}^{-}$concentration is low, the $I_{\text {scc }}$ growth trend is more pronounced. When $\mathrm{Cl}^{-}$concentration is greater than $80,000 \mathrm{mg} / \mathrm{L}$, 316L stainless steel exhibits a certain degree of chloride SCC under the experimental conditions. 


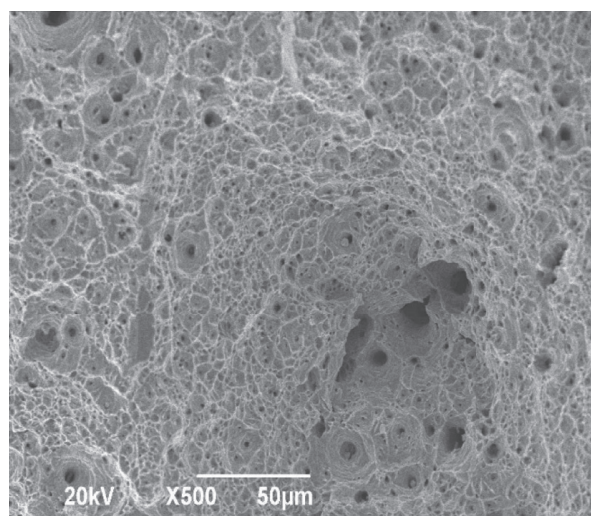

(a)

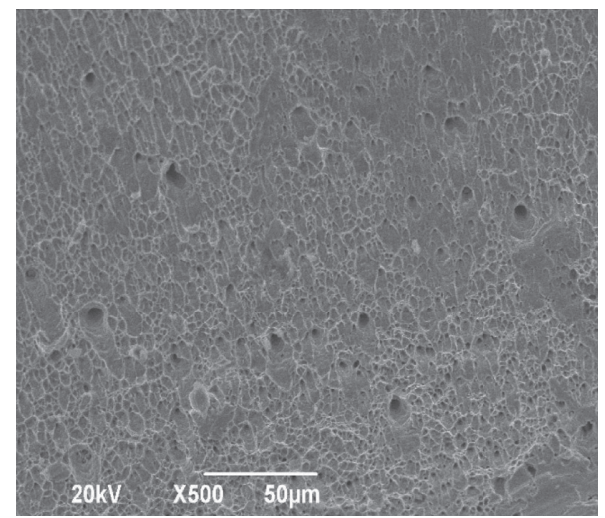

(b)

Figure 10: SEM images of fracture surface morphology of tensile test coupons $\left(\mathrm{Pco}_{2}=0.1 \mathrm{Mpa}, \mathrm{T}=65^{\circ} \mathrm{C}\right):(\mathrm{a}) \mathrm{Cl}-60,000 \mathrm{mg} / \mathrm{L}$; (b) $\mathrm{Cl}^{-}=80,000 \mathrm{mg} / \mathrm{L}$.

TABLE 7: Main mechanical properties of 316L stainless steel at different $\mathrm{Cl}^{-}$concentrations.

\begin{tabular}{lcccc}
\hline $\mathrm{Cl}^{-}(\mathrm{mg} / \mathrm{L})$ & Tensile strength $\sigma_{b}(\mathrm{MPa})$ & Reduction of area $\psi(\%)$ & Elongation $\delta_{5}(\%)$ & Fracture time $(\mathrm{h})$ \\
\hline 60,000 & 532.0 & 83.7 & 49.5 & 35.1 \\
80,000 & 529.0 & 81.8 & 46.7 & 33.6 \\
$1,00,000$ & 517.0 & 79.6 & 45.8 & 31.7 \\
$1,20,000$ & 524.0 & 76.2 & 45.7 & 32.6 \\
\hline
\end{tabular}

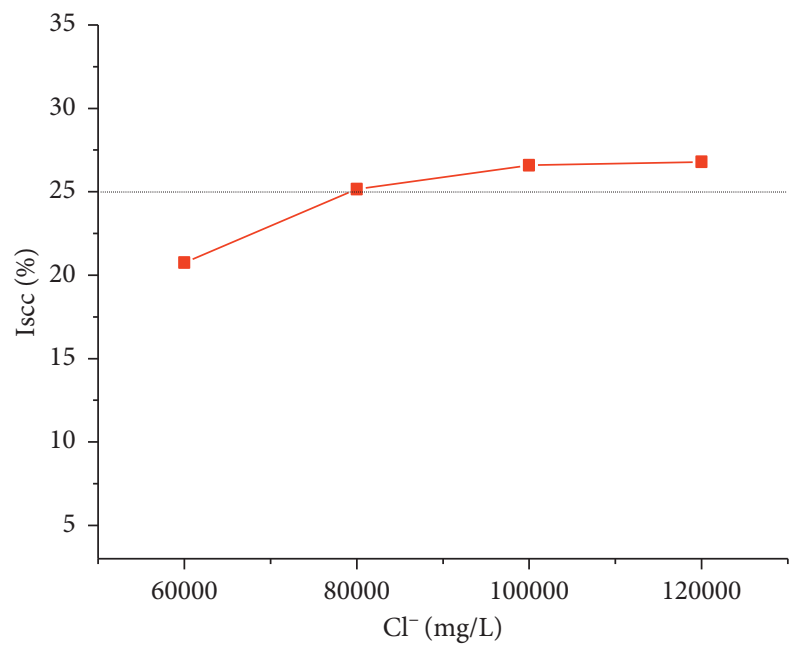

Figure 11: Sensitivity index of stress corrosion cracking of $316 \mathrm{~L}$ stainless steel at different $\mathrm{Cl}^{-}$concentrations.

\section{Conclusions}

(1) The slow-strain-rate tensile test results demonstrate that when the partial pressure of $\mathrm{CO}_{2}$ is between 0 and $0.3 \mathrm{MPa}$; the effect of increasing $\mathrm{CO}_{2}$ content on the chloride SCC sensitivity of $316 \mathrm{~L}$ stainless steel is not apparent.

(2) In the range of $25-85^{\circ} \mathrm{C}$, as the temperature rises, the chloride SCC sensitivity of $316 \mathrm{~L}$ stainless steel increases and $I_{\text {scc }}$ changes obviously.

(3) When $\mathrm{Cl}^{-}$concentration increases from 60,000 to $1,20,000 \mathrm{mg} / \mathrm{L}$, the chloride SCC sensitivity of 316L stainless steel tensile specimens also increases to some extent, but when $\mathrm{Cl}^{-}$concentration is greater than $1,00,000 \mathrm{mg} / \mathrm{L}$, the $I_{\mathrm{scc}}$ value no longer changes significantly.

(4) The degree of influence of the three factors on the experimental results is as follows: temperature $>\mathrm{Cl}^{-}>\mathrm{CO}_{2}$. In this experiment, when the $\mathrm{CO}_{2}$ partial pressure is $0.1 \mathrm{MPa}$, the temperature is $65^{\circ} \mathrm{C}$, and the $\mathrm{Cl}^{-}$concentration is $1,20,000 \mathrm{mg} / \mathrm{L}$, $I_{\text {scc }}$ of $316 \mathrm{~L}$ tensile samples has a maximum of $26.8 \%$.

\section{Data Availability}

The data used to support the article are included in the manuscript.

\section{Conflicts of Interest}

The authors declare that they have no conflicts of interest.

\section{Acknowledgments}

The authors gratefully acknowledge this work's sponsorship by the Sichuan Gas East Natural Gas Co., Ltd.

\section{References}

[1] H. Cheng, The Study on 304 Stainless Steel Susceptibility of Pitting Corrosion and Stress Corrosion Cracking in Circulating Cooling Water Containing Chloride Ion, Beijing University of Technology, Chaoyang, China, 2008.

[2] M. Ueda, K. Nakamura, N. Hudson, M. Z. Ibrahim, K. Selamat, and P. S. Chen, "Corrosion behavior of super $13 \mathrm{Cr}$ martensitic stainless steels in completion fluids," in 
Proceedings of the Corrosion 2003, San Diego, CA, USA, March 2003.

[3] F. Manica, "The effect of environmental modification on the sulphide stress corrosion cracking resistance of $13 \mathrm{Cr}$ martensitic stainless steel in $\mathrm{H}_{2} \mathrm{~S}-\mathrm{CO}_{2}-\mathrm{Cl}^{-}$systems," Corrosion Science, vol. 27, no. 10-11, pp. 1225-1237, 1987.

[4] K. B. Liu, W. M. Zhou, T. C. Zhi et al., "Stress corrosion cracking behavior of super $13 \mathrm{Cr}$ stainless steel in $\mathrm{CO}_{2}$ containing $\mathrm{CaCl}_{2}$ completion fluid," Chemical Engineering of Oil \& Gas, vol. 36, no. 3, pp. 222-226, 2007.

[5] Y. Li, Study on the Stress Corrosion of 316L Stainless Steel in $\mathrm{NaCl}$ Solution, Harbin Engineering University, Harbin, Heilongjiang, China, 2011.

[6] Y. Li, K. W. Fang, and F. H. Liu, "Influence of $\mathrm{Cl}^{-}$on development behavior from pitting corrosion to stress corrosion cracking of 304L stainless steel," Corrosion \& Protection, vol. 33, no. 11, pp. 955-959, 2012.

[7] ISO, GB/T 15970.7-2017, Corrosion of metals and alloys-Stress Corrosion Testing-Part 7: Slow Strain Rate Testing, ISO, Geneva, Switzerland, 1989.

[8] J. H. Wen, C. S. Hu, K. Xiao, and J. Wang, "Corrosive pitting behavior of 316L stainless steel welding seam," Physical Testing and Chemical Analysis (Part A: Physical Testing), vol. 45, no. 4, pp. 205-207, 2009.

[9] H. W. Lv, S. G. Dong, J. J. Wang et al., "Electrochemical behaviors of the 316L stainless steel welding seam corrosion," Science \& Technology Review, vol. 31, no. 5-6, pp. 25-28, 2013.

[10] S. P. Dong, J. G. Yang, J. G. Yuan et al., "Experimental research on SCC and glavano-chenistry of steel used in vessel in $\mathrm{H}_{2} \mathrm{~S}$ mediator," Pressure Vessels-Advanced Technology of Pressure Vessels, pp. 190-197, Beijing Machinery Industry Press, Beijing, China, 2005. 